\title{
INVESTIGATING EFFECTS IN GNSS STATION COORDINATE TIME SERIES
}

\author{
Diana Haritonova ${ }^{1}$, Janis Balodis ${ }^{2}$, Inese Janpaule ${ }^{3}$ \\ ${ }^{1,2,3}$ Institute of Geodesy and Geoinformation, University of Latvia, Raina Boulevard 19, LV-1586 Riga, Latvia \\ ${ }^{1,3}$ Department of Geomatics, Riga Technical University, Azenes Str. 16/20, LV-1048 Riga, Latvia \\ E-mail.1 diana.haritonova@rtu.lv; ${ }^{j}$ janis.balodis@lu.lv; ${ }^{3}$ inese.janpaule@rtu.lv
}

\begin{abstract}
The vertical and horizontal displacements of the Earth can be measured to a high degree of precision using GNSS. Time series of Latvian GNSS station positions of both the EUPOS ${ }^{\circledR}$-Riga and LatPos networks have been developed at the Institute of Geodesy and Geoinformation of the University of Latvia (LU GGI). In this study the main focus is made on the noise analysis of the obtained time series and site displacement identification. The results of time series have been analysed and distinctive behaviour of EUPOS ${ }^{\circledR}$-Riga and LatPos station coordinate changes have been identified. The possible dependences of GNSS station coordinate distribution on EPN station problems, seismic activity of some areas of Latvia and solar activity have been considered and are presented in this paper.
\end{abstract}

Keywords: GNSS, permanent networks, time series analysis, station displacements.

\section{Introduction}

Within the framework of EUPOS $^{\circledR}$ regional development project, two GNSS station networks have been developed in Latvia - LatPos (Zvirgzds, 2007) and EUPOS $^{\circledR}$-Riga (Abele, 2008), which have been operating since 2006.

The EUPOS $^{\circledR}$ initiative is an international expert group of public organisations coming from the field of geodesy, geodetic survey and cadastre. Partners from 19 countries of Central and Eastern Europe work on the provision of compatible spatial reference infrastructures by using the Global Navigation Satellite Systems (GNSS) GPS, GLONASS and as soon as it is available GALILEO by operating Differential GNSS EUPOS ${ }^{\circledR}$ reference station services (Rosenthal, 2008). The EUPOS ${ }^{\circledR}$ services allow a high accuracy and reliability for positioning and navigation and provide a wide range of geoinformation applications on this basis.

EUPOS $^{\circledR}$-Riga and LatPos networks are primarily geodetic reference networks established for navigation purposes. But according to the worldwide experience and trends in space geodesy it is commonly accepted to use GNSS stations for studies of geophysical processes. The vertical and horizontal displacements of the Earth can be measured to a high degree of precision using GNSS.

Time series of GNSS station positions of both EUPOS $^{\circledR}$-Riga and LatPos networks have been developed at the Institute of Geodesy and Geoinformation of the University of Latvia (LU GGI). Coordinates have been obtained for 5-year long observation period.

Using the data of the reference stations from EUREF Permanent Network (EPN) in the surroundings of Latvia and the input data sets from IGS data bases, the Bernese GPS Software Version 5.0 has been used to compute daily network solutions (Balodis, 2011).

In this study the main focus is made on the noise analysis of the EUPOS ${ }^{\circledR}$-Riga and LatPos time series and site displacement identification.

The results of time series have been analysed and distinctive behaviour of EUPOS $^{\circledR}$-Riga and LatPos station coordinate changes have been identified.
The possible dependences of GNSS station coordinate distribution on EPN station problems (outliers), seismic activity of some areas of Latvia and solar activity have been considered and are presented in this paper.

\section{Data selection and processing}

The EUREF Permanent Network (EPN) is a network of continuously operating GNSS reference stations maintained on a voluntary basis by EUREF members. The primary purpose of the EPN is to provide access to the European Terrestrial Reference System (ETRS89) by making publicly available the tracking data as well as the precise coordinates of all the EPN stations (Bruyninx et al. 2011).

Based on the series of the regularly updated EPN multi-year position and velocity solution, the EPN stations are categorized taking into account the station quality and the length of the available observation time span (Kenyeres, 2009):

- Class A: station positions have a $1 \mathrm{~cm}$ accuracy at all epochs of the time span of the used observations,

- Class B: station positions have a $1 \mathrm{~cm}$ accuracy at the epoch of minimal variance of each station.

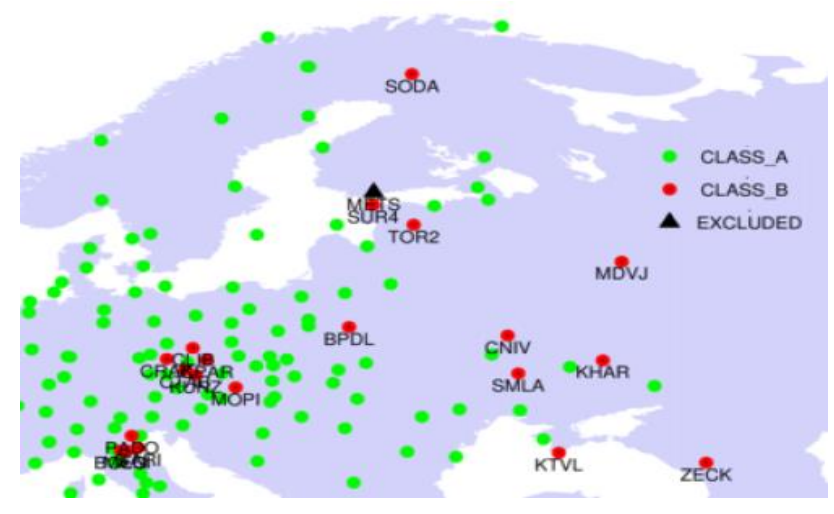

Fig. 1. EPN site categorisation, version C1680 (Kenyeres, 2012). 


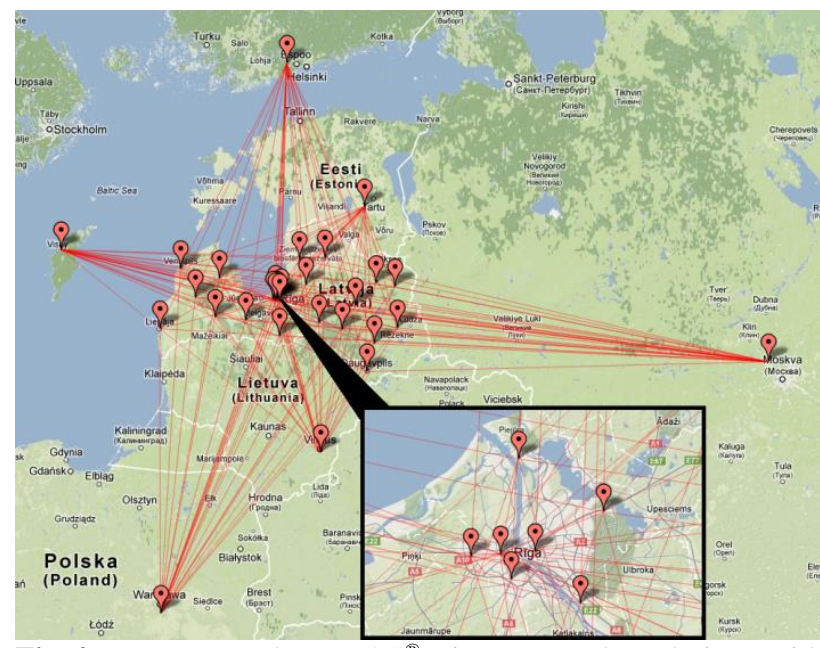

Fig. 2. LatPos and EUPOS ${ }^{\mathbb{B}}$-Riga network solution with reference stations from EPN: JOZE, MDVJ, METS, RIGA, TORA, VISO, VLNS.
Only class A stations are recommended to be used as the reference stations for ETRS89 densifications (Bruyninx et al. 2012).

The EPN station categorisation is shown in Fig. 1: stations indicated in green are Class A stations, stations indicated in red belong to Class $\mathrm{B}$, and the black triangle represents station METS, which is temporarily excluded from the combination due to site tracking problems.

In the framework of research in various daily solutions the selection of reference stations has been miscellaneous. Most frequently 5-7 reference stations (see Fig. 2) were selected from a set of stations: BPDL, BOGO, BOR1, BYDG, CNIV, JOEN, JOZE, KURE, MDVJ, METS, POLV, PULK, REDZ, RIGA, SPT0, SUUR, SUR4, SWKI, TOIL, TORA, TOR2, VAAS, VIS0, VLNS, WROC. The reason of such miscellaneous selection of reference stations in various days is data acceptance by the Bernese software depending on the quality of the particular station data on a particular day (Balodis, 2012).

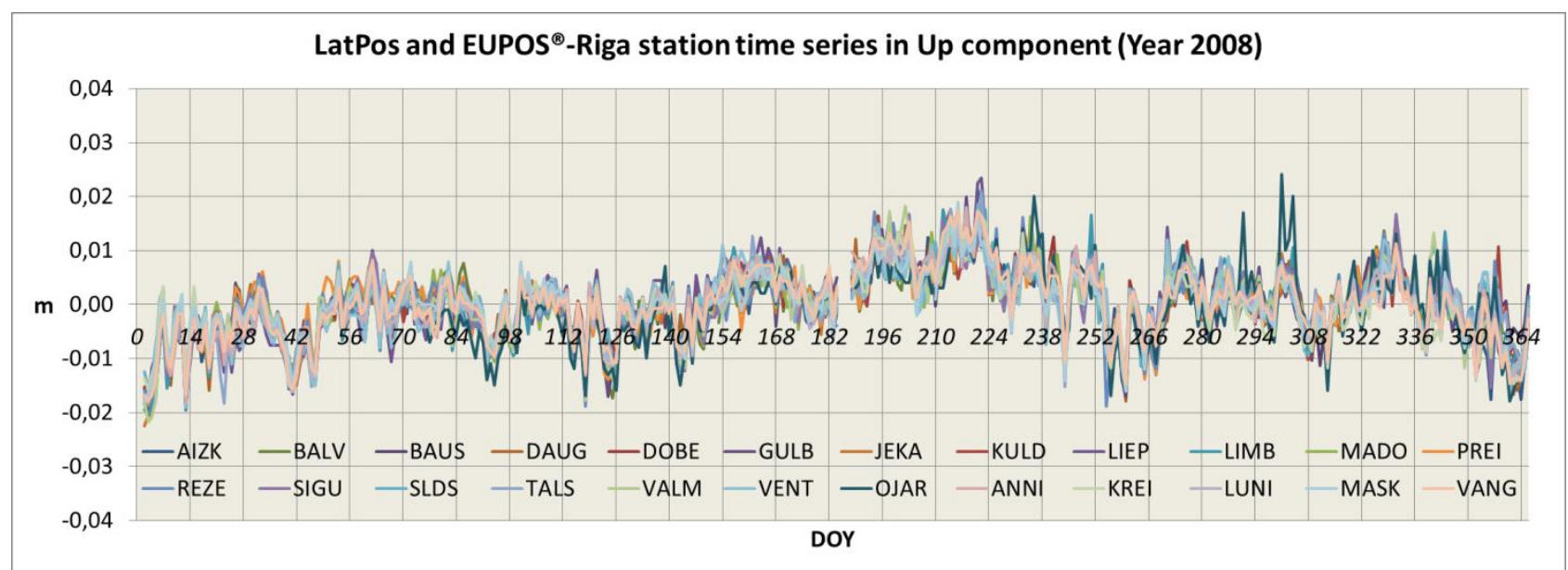

Fig. 3. LatPos and EUPOS ${ }^{\circledR}$-Riga station time series of the year 2008 in Up component.

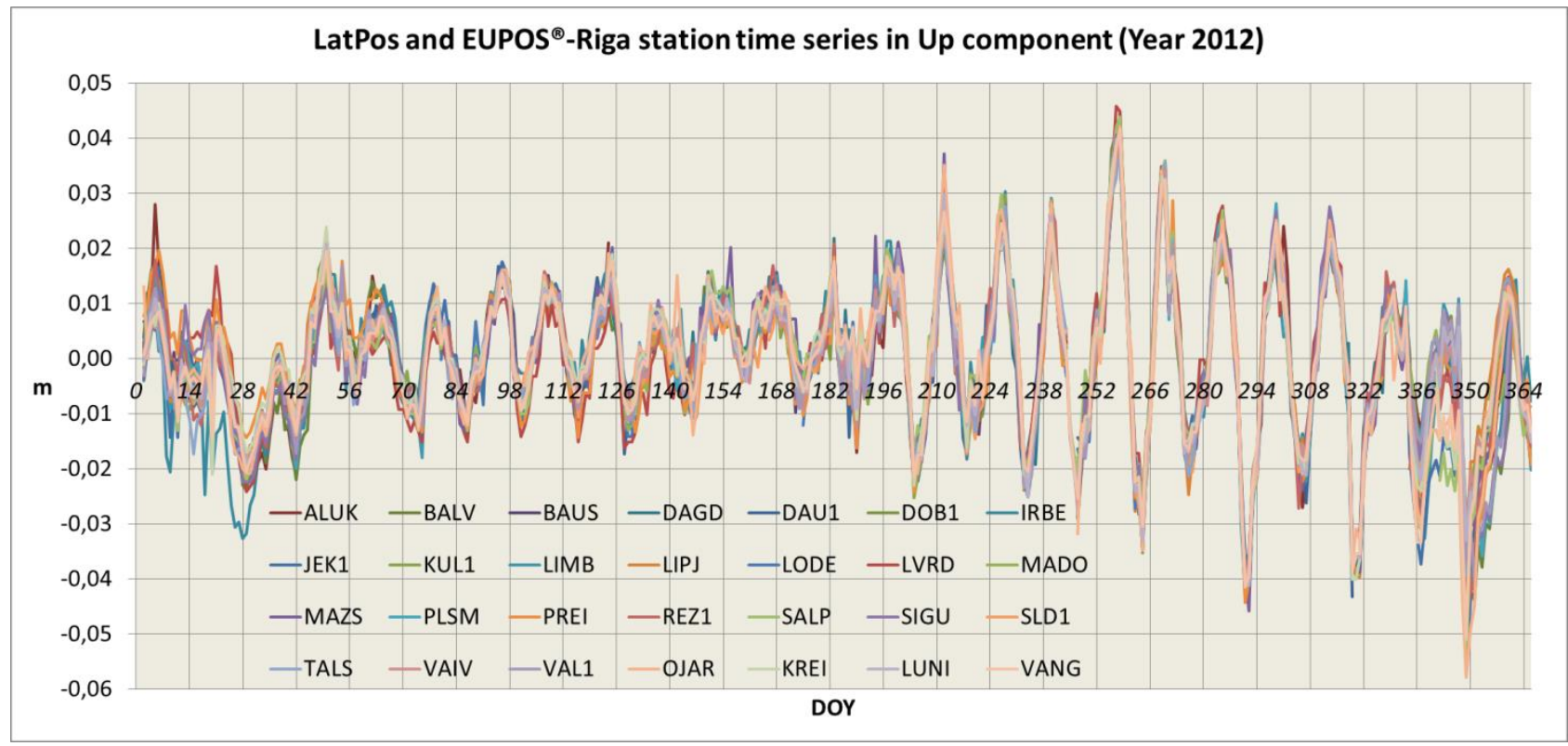

Fig. 4. LatPos and EUPOS ${ }^{\circledR}$-Riga station time series of the year 2012 in Up component. 
In spite of the recommendation to use only Class A stations as fiducial (or reference) stations for the densification of the ETRS89, station MDVJ belonging to Class B and station CNIV were used as reference stations in network solutions. CNIV station used to be Class A station and then it was categorized into class B due to high seasonal signal (Kenyeres, 2012). The reason for such decision is an insufficient number of EPN easternmost reference stations for the territory of Latvia.

Station METS, temporarily excluded from the EPN series at GPS week 1632 until week 1680, was also treated as a reference station for short observation period (from day 138 to 176 of the year 2011) within the interval of site exclusion.

Besides, stations TOR2 and SUR4 were used in the calculation process for the years 2011 and 2012. The above-mentioned stations also belong to Class B due to the short period of the available observations (Kenyeres, 2009).

The daily solutions yielding the time series of $\mathrm{X}, \mathrm{Y}$ and $\mathrm{Z}$ geocentric coordinate variations for EUPOS $^{\circledR}$-Riga and LatPos permanent GNSS network stations have been obtained applying Bernese GPS Software, Version 5.0, which is one of the most comprehensive GNSS softwares for scientific purposes. The standard data sets were taken from IGS data bases - ionosphere and troposphere parameters, satellite orbits, satellite clock corrections, as well as the Earth rotation parameters.

The results of GNSS data processing are station coordinates of the daily solution in the IGS05 coordinate system and since GPS week 1632 (17 April 2011) in the new IGS08 frame (Rebischung, 2011). First of all, the obtained coordinates have been transformed to the European Terrestrial Reference Frame ETRS89 (Boucher, Altamimi, 2008), and then to the Latvian Geodetic Coordinate System LKS-92.

\section{Results and discussion}

Time series of GNSS station coordinates of both EUPOS $^{\circledR}$-Riga and LatPos networks have been obtained for 5-year long observation period - from the year 2008 to 2012 inclusive, using the data from 41 regional GNSS stations altogether. Most of them have been renamed and replaced within relatively small areas during the mentioned period of time. That is the reason of data discontinuity.

GNSS station time series in the Up component for the year 2008 (Fig. 3) and 2012 (Fig. 4) are shown in the charts above. Each chart represents coordinate residuals with respect to the mean position for each year separately.

\section{Overview of data quality}

At a single glance, an essentially different data distribution for the year 2008 can be observed in comparison with obtained results for the year 2012. Fig. 4 shows that EUPOS $^{\circledR}$-Riga and LatPos time series have periodic variations with about two week step. The reason is not yet understood, but such oscillating data resemble displacements due to mass transfers on the Earth's surface caused by the tide effect.

Sample autocorrelation function has been used to demonstrate sharp distinctions in the Up component time series of LUNI station for the year 2008 (Fig. 5) and 2012 (Fig. 6).

The sample autocorrelation function gives an illustrative example of variations in the time series. It is defined by

$\mathrm{r}(k)=\frac{c(k)}{c(0)}$,

where $c(0)$ is the variance and $c(k)$ is the autocovariance function, which can be estimated by

$c(k)=\frac{1}{N} \sum_{t=1}^{N-k}\left(x_{t}-\bar{x}\right)\left(x_{t+k}-\bar{x}\right)$,

where $\bar{x}$ is the mean of the observed time series.

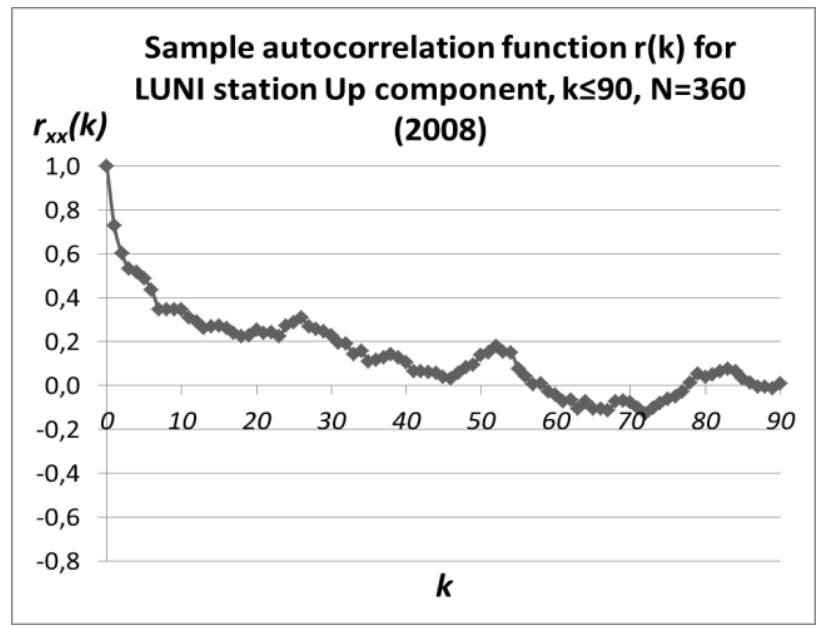

Fig. 5. Sample autocorrelation function for LUNI station time series of the year 2008 in the Up component.

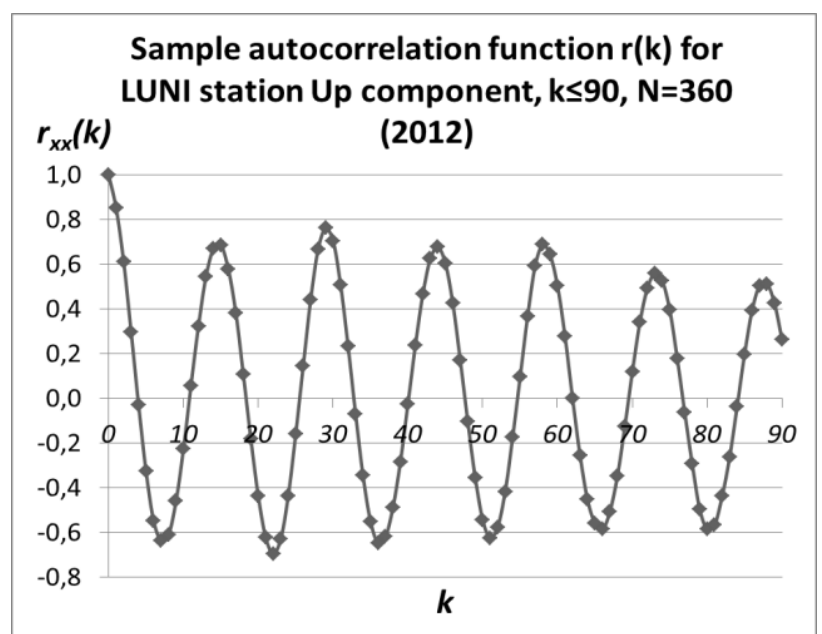

Fig. 6. Sample autocorrelation function for LUNI station time series of the year 2012 in the Up component.

The autocorrelation function gives a visual picture of the way in which the dependence in the series damps out with the lag or separation $k$ between points in the series (Jenkins, Watts, 1968). 
Fig. 3 shows that the series are smooth, and this is reflected in an autocorrelation function which damps out smoothly with lag (see Fig. 5). The autocorrelation function shown in Fig. 6 reflects the periodic behaviour and consists of a sine wave with a period of about 15 days, which does not damp out smoothly.

After analysing coordinate time series of all Latvian GNSS stations from the year 2008 to 2012 inclusive, the daily observation standard deviations have been calculated with a $95 \%$ confidence level: $\sigma= \pm 1 \mathrm{~cm}$ in horizontal plane and $\sigma= \pm 3 \mathrm{~cm}$ in the Up component. It means that although we can observe relatively highamplitude periodic variations, the accuracy of daily station positions is several times smaller.

\section{Solar activity and its influence}

Another significant factor is the data growing amplitude with a maximum during 120-day period in the year 2012, from day 200 to 320 . This might be caused by increasing solar activity.

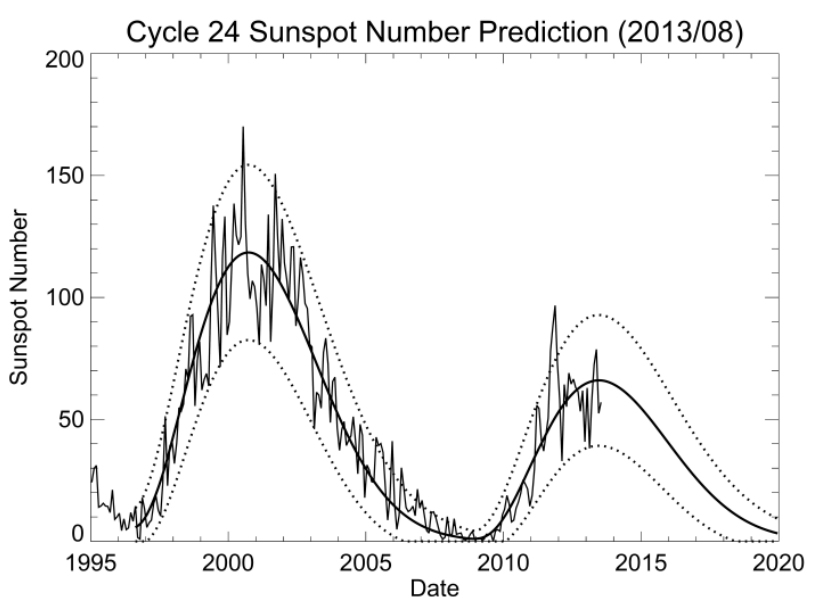

Fig. 7. Sunspot cycle 23 and predictions for cycle 24 from NASA's Marshall Space Flight Center.

Solar activity and the quantity of emissions from the Sun are highly correlated with the number of sunspots on its surface. The number of sunspots generally follows a cycle of about 11 years as it can be seen in Fig. 7. Solar cycle 24 began on January 4, 2008.

Worldwide practices of observations of solar activity show that the density of the solar wind increases with the increase of the number of sunspots. Also, with a large number of sunspots, solar flares and coronal mass ejections (CMEs) happen more frequently. Ionospheric storm activity is more common when the number of sunspots is high, and this activity increases the variability in ionospheric delays. This all adds up to an increased number of free electrons in the ionosphere and a larger variability, which provides a larger and more variable signal delay for all types of GNSS-based positioning, navigation, and timing during periods with high sunspot numbers (Jensen, Mitchell, 2011).

During the period from the year 2007 until 2009 it was a time interval with a low number of sunspots. During the next four years, the number of sunspots has been increasing, and this will be followed by a decrease until a new period of low solar activity in 2019-2020.

\section{GNSS network solution and its influence}

Analysing reference station selection for network solutions and EPN station problems (outliers), remarkable coherence of the mentioned factors with postprocessing result quality was found for some observation periods.

For example, outstanding values can be observed in the Up component time series of weekly EPN solution for station MDVJ, which are cancelled from the official multi-year EPN solution. These peaks correspond to the beginning of the years 2009 and 2011 as shown in Fig. 8.

The winter time usually correlates with snow coverage of some GPS antennae (Kenyeres, Bruyninx, 2009). It might be one of the reasons of the mentioned peaks in the time series of station MDVJ.

During the processing MDVJ station data have been partially used in these outlier intervals.

In the case of the year 2009, EUPOS ${ }^{\circledR}$-Riga and LatPos station coordinate time series have outstanding values in the Up component exactly on those days, when MDVJ station was used as a reference station, it is from day 26 to 36 of the year (see Fig. 9).

And in the case of the beginning of the year 2011, MDVJ station was fixed for datum definition only in the first week of January. The outstanding data distribution, which corresponds to the period of one week, is shown in Fig. 10.
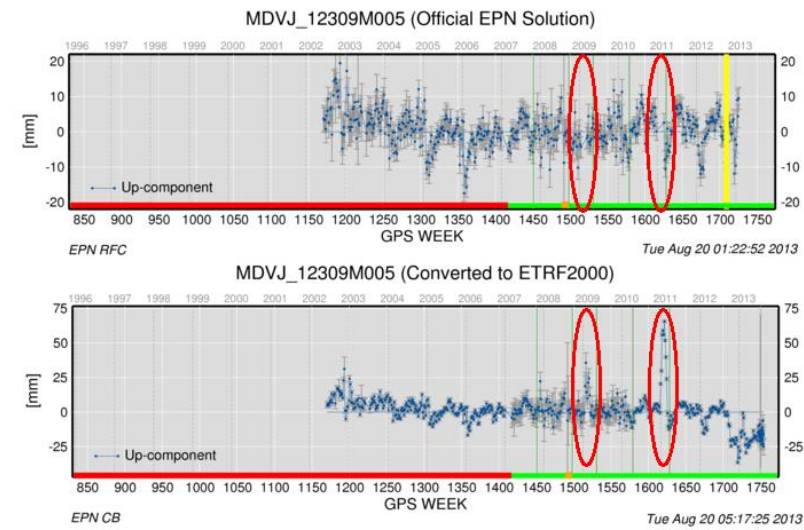

Fig. 8. MDVJ station Up-differences with respect to the mean position: official multi-year EPN solution and weekly EPN solution (EPN Central Bureau).

For other reference stations similar outliers have not been detected, or station data have not been used in the time of outstanding coordinate values (Kenyeres, Bruyninx, 2004). 


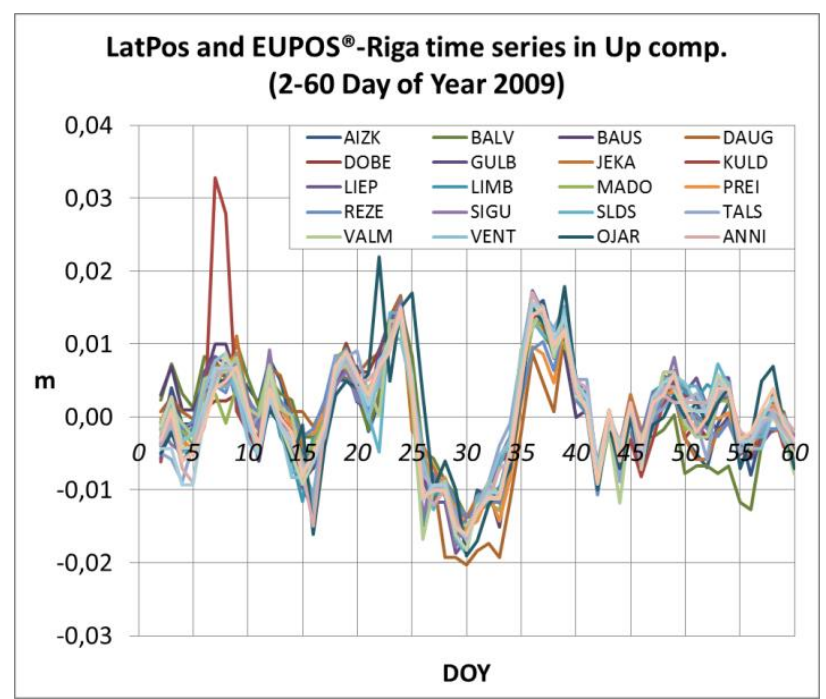

Fig. 9. EUPOS ${ }^{\circledR}$-Riga and LatPos station Up-differences with 10-day long outstanding observations.

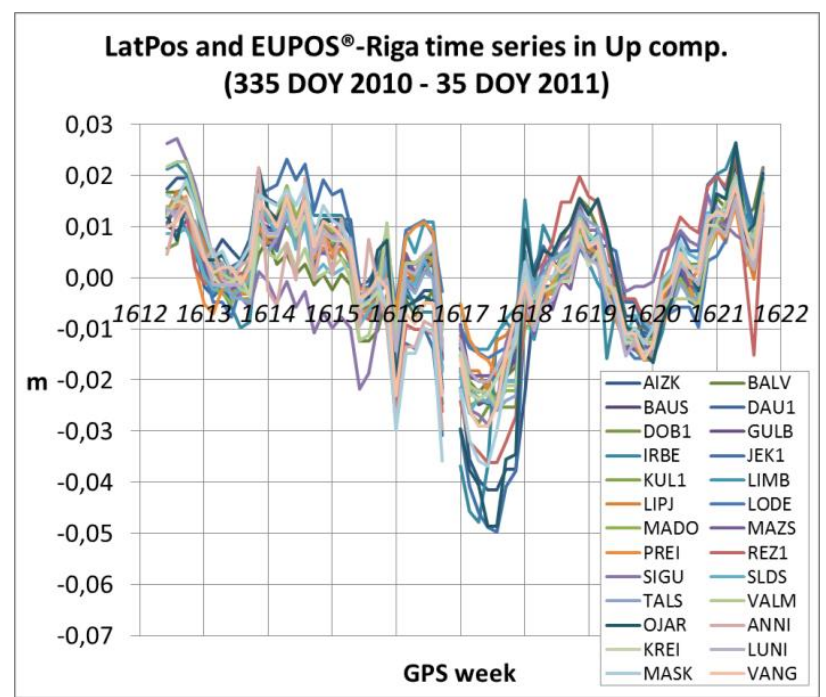

Fig. 10. EUPOS $^{\circledR}$-Riga and LatPos station Up-differences with one week long outstanding observations.
Kinematic processing results

Previously described outliers correspond for all stations for the observed interval with high noise in the time series.

But there are also some single stations, which have extreme values independently from other stations. Most of them have outstanding coordinate values for one observation day. Such values can be explained by random errors or antenna problems. Stations with extreme values in their time series during longer observation interval are of more interest.

For example, the data shown in Fig. 9 can be used. LatPos network stations KULD and BALV demonstrate dissimilar coordinates in the Up component. In the case of station KULD (in red), outliers can be observed for two days, and in the case of station VALM (in green) for 9-day long observation interval.

To understand the nature of influences, the Bernese GPS Software Version 5.0 has been used to compute subdaily coordinate time series. Processing of mixed kinematic and static, stations has been performed in the same solution allowing to process data from several stations in baseline mode - one of them kinematic, the others static (Beutler et al. 2007).

Kinematic processing results of the data from station KULD are shown in Fig. 11.

The 7th and 8th day of the year 2009 are those, when outliers are observed in daily time series. Sub-daily noise in kinematic time series, which correspond to the mentioned days, is well visible in Fig. 11. Coordinate variations are observed during all 2-day long period. Sub-daily noise in the Up component correlates with the coordinate changes in North and East components as well.

There can be various reasons for such data distribution of a single station: temporal multipath effect, monumentation weakness, seismic activity, etc. Deeper investigation and additional information are needed to understand such biases in time series.

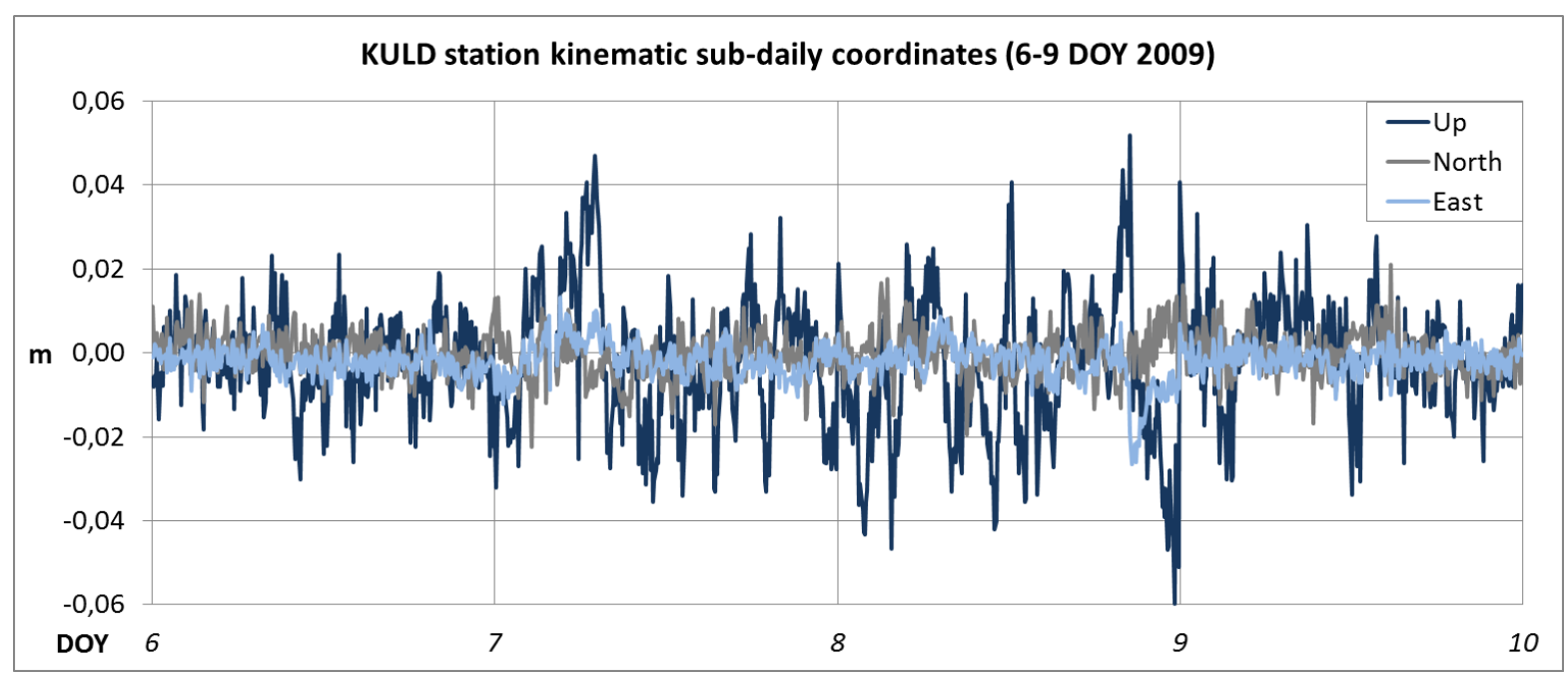

Fig. 11. Kinematic processing results of the data from LatPos station KULD with outstanding coordinates in the daily series. 


\section{GNSS station horizontal displacements}

Analysing GNSS station 5-year long time series in East component, dissimilar data distribution was detected for stations MASK and DAUG.

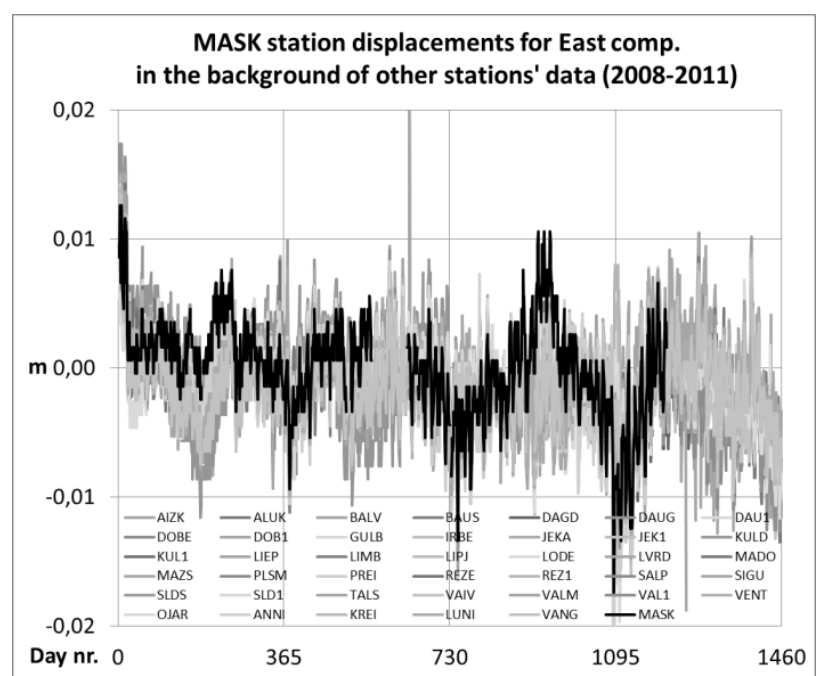

Fig. 12. MASK station East-differences with respect to the mean position for 4-year long observation period.

Against the background of other stations the EUPOS ${ }^{\circledR}$ Riga station MASK, indicated in black in Fig. 12, has a maximum amplitude of East component after the period of station disappearance for 10 weeks (from GPS week 1540 to 1550 ), from GPS week 1551 to 1632 .

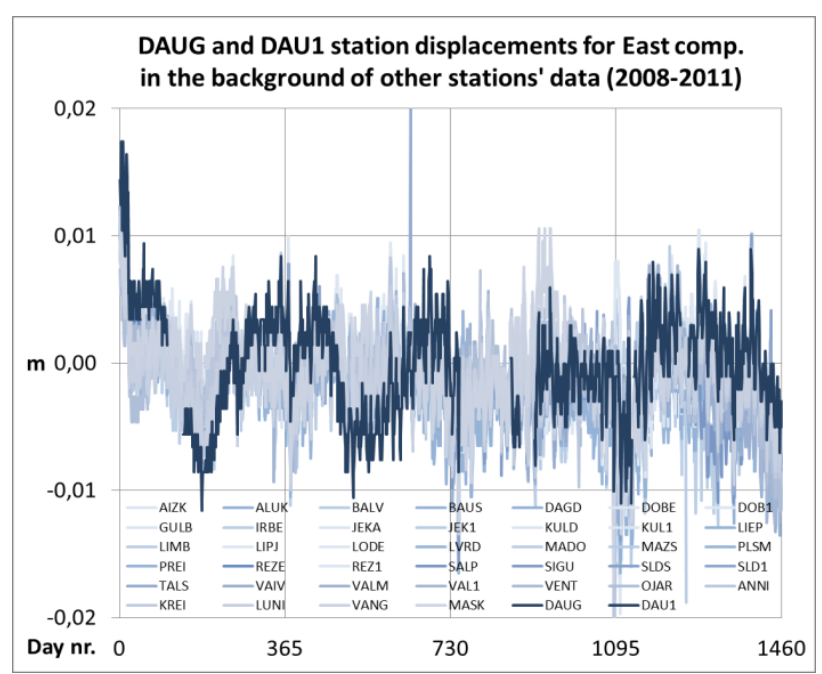

Fig. 13. DAUG and DAU1 station East-differences with respect to the mean position for 4-year long observation period.

In the case of the LatPos station DAUG maximum data distribution in the East component is also observed. Fig. 13 shows the processing results of two stations: DAUG and DAU1 (in blue). The first two years of observations (2008 and 2009) correspond to the station DAUG, which then has been replaced within the city of Daugavpils and renamed DAU1. Fig. 13 shows that the maximum amplitude of coordinate variations in the East component belongs only to the site DAUG.

It is also interesting to note that both stations MASK and DAUG are located close to the zones with seismic activity. The Daugavpils district, where stations DAUG and DAU1 are located, is exposed to geohazard risks in particular (Soms, Laizans, 2011).

There are several established and potential seismic zones identified in the territory of Latvia. Moreover, there are relatively unfavourable local engineering-geological conditions in Latvia - unconsolidated soil and high groundwater level. These negative conditions increase the Earth's surface oscillations due to resonance effect (Nikulins, 2011).

In other words, Latvia is located in the area of low seismic activity. But it has been proved that in two zones of earthquake source (Daugavpils and Bauska) seismic shaking intensity can exceed grade 7 according to MSK-64 scale of 12 intensity degrees, and in 12 seismic zones the level of seismic shakings can reach an intensity of 6 degrees (Nikulins, 2007).

\section{Conclusions}

The results of EUPOS ${ }^{\circledR}$-Riga and LatPos time series have been analysed for the observation period from the year 2008 to 2012 inclusive.

Quite different data distribution of the year 2008 can be observed in comparison with the obtained results for other years. In the case of the year 2008, EUPOS ${ }^{\circledR}$-Riga and LatPos station Up-component series are smooth, but for other observation years Up-component data demonstrate periodic behaviour.

The daily observation standard deviations of all Latvian GNSS stations have been calculated with a $95 \%$ confidence level: $\sigma= \pm 1 \mathrm{~cm}$ in horizontal plane and $\sigma=$ $\pm 3 \mathrm{~cm}$ in the Up component. Although relatively highamplitude periodic variations can be observed, the accuracy of daily station positions is several times smaller.

From the year 2008 Latvian GNSS station Updifferences were increasing until a maximum in the fall of 2012. This might be caused by increasing solar activity. At the same time, the number of sunspots has been rising with variability in ionospheric delays.

Analysing station selection for network solutions, remarkable influence of reference station problems on the quality of post-processing results was found.

Distinctive behaviour of EUPOS ${ }^{\circledR}$-Riga and LatPos station coordinate changes was identified. Deeper investigation and additional information are needed to understand sub-daily biases in kinematic time series.

Analysing GNSS station 5-year long time series in East component, dissimilar data distribution was detected for stations MASK and DAUG, which are located close to the zones with seismic activity.

EUPOS $^{\circledR}$-Riga and LatPos networks are primarily geodetic reference networks, but their results are also used for geophysical studies.

\section{References}

Abele, M.; Balodis, J.; Balodis, K..; Normanda, M.; Janpaule, I.; Mitrofanovs, I.; Rubans, A.; Silabriedis, G.; Zarins, A., 2008. Implementation of New Positioning System in Riga. International Symposium EUREF. Brussels, June pp. 18-20. 
Balodis, J.; Haritonova, D.; Janpaule, I.; Morozova, K.; Normanda, M.; Silabriedis, G.; Zarinjsh, A.; Zvirgzds, J., 2011. GNSS Network Station's Time Series Analyses. Proceedings of the International Symposium on Global Navigation Satellite Systems, Space-Based and GroundBased Augmentation Systems and Applications. Berlin, Germany, 10-11 October 2011.

Balodis, J.; Janpaule, I.; Haritonova, D.; Normand, M.; Silabriedis, G.; Zarinjsh, A.; Zvirgzds, J., 2012. GNSS Network Time Series Analysis. EGU General Assembly 2012. Vienna, Austria 22-27 April 2012.

Beutler, G.; $\quad$ Bock, H.; $\quad$ Dach, R.; $\quad$ Fridez, P.; $\quad$ Gäde, A.; Hugentobler, U.; Jäggi, A.; Meindl, M.; Mervart, L.; Prange, L.; Schaer, S.; Springer, T.; Urschl, C.; Walser, P., 2007. User manual of the Bernese GPS Software Version 5.0. Astronomical Institute, University of Bern.

Boucher, C.; Altamimi, Z., 2008. Memo: Specifications for reference frame fixing in the analysis of a EUREF GPS campaign [online], [cited 28 August 2013]. Available at: http://etrs89.ensg.ign.fr/memo-V7.pdf

Bruyninx, C.; Altamimi, Z.; Caporali, A.; Kenyeres, A.; Lidberg, M.; Stangl, G.; Torres, J. A., 2012. Guidelines for EUREF Densifications [online], [cited 28 August 2013]. Available at: $\mathrm{ftp} / / /$ epncb.oma.be/pub/general/Guidelines_for_EUREF_Den sifications.pdf

Bruyninx, C.; Baire, Q.; Legrand, J.; Roosbeek, F., 2011. The EUREF Permanent Network: Recent Developments and Key Issues [online], [cited 28 August 2013]. Available at: http://www.epncb.oma.be/_documentation/papers/

Griffiths, J., 2011. Advice for coping with the change to IGS08+igs08.atx. IGSMAIL-6356 [online], [cited 28 August 2013]. Available at:

http://igscb.jpl.nasa.gov/pipermail/igsmail/2011/006348.html

Jenkins, G. W.; Watts, D. G., 1968. Spectral analysis and its applications. San Francisco: Holden-Day, 1968.

Jensen, A. B. O.; Mitchell, C., 2011. GNSS and the Ionosphere: What's in Store for the Next Solar Maximum? GPS World, 22(2), February 2011.

Kenyeres, A., 2009. Maintenance of the EPN ETRS89 coordinates. EUREF TWG 2009 Spring Meeting. Budapest, February pp. 26-27, 2009.
Kenyeres, A., 2012. The implementation of IGSO8 in the EPN ETRS89 maintenance products [online], [cited 28 August 2013]. Available at:

http://www.epncb.oma.be/_productsservices/coordinates/

Kenyeres, A.; Bruyninx, C., 2004. EPN coordinate time series monitoring for reference frame maintenance. GPS Solutions, 8(4), pp.200-209.

http://dx.doi.org/10.1007/s10291-004-0104-8

Kenyeres, A.; Bruyninx, C., 2009. Noise and Periodic Terms in the EPN Time Series. Geodetic Reference Frames, IAG Symposia, 134, pp.143-148.

Nikulins, V., 2007. Seismotectonic conditions and seismic hazards in Latvia - doctoral candidate's work. Riga: University of Latvia.

Nikulins, V., 2011. Assessment of the seismic hazard in Latvia. Version of 2007 year. Scientific Journal of Riga Technical University. Material Science and Applied Chemistry, 24, pp. 110-115.

Rebischung, P., 2011. Upcoming switch to IGS08/igs08.atx. IGSMAIL-6354 [online], [cited 28 August 2013]. Available at: http://igscb.jpl.nasa.gov/pipermail/igsmail/2011/006346.html

Rosenthal, G., 2008. European Position Determination System Status and Activities. Third Meeting of the International Committee on Global Navigation Satellite Systems. Pasadena, U.S.A. 8 - 12 December 2008.

Soms, J.; Laizans, K., 2011. Application of Geographic Information Systems (GIS) in Analysis of Geological Risk Factors and Assessment of Geohazards in Daugavpils and Ilukste Districts. Proceedings of the $8^{\text {th }}$ International Scientific and Practical Conference. Environment. Technology. Resources. 1, pp. 24-30.

Zvirgzds, J., 2007. Geodetic measurements using GPS base station system LatPos. Geomatics, 11, RTU, Riga, pp. 81-89.

\section{Acknowledgements}

We would like to express our gratitude to Izolde Jumare for her support in data processing.

The research was funded by ERAF, project No 2010/0207/2DP/2.1.1.1.0/10/APIA/VIAA/077. 